\title{
Systemic Introduction to Technology Planning in the Context of Technology Competitiveness
}

\author{
Jemala Marek
}

\begin{abstract}
The concept of a technology strategy (TS) has been developing in the literature of Technology management since the 1970s. TS has been defined as a set of technology and related objectives, variant scenarios, technology roadmaps, targeting practices, and know-how aimed at an adequate specification of the desired long-term development of a technological system and related processes (R\&D, supply, sales, control, service, etc.). This article has two main scientific goals. The first goal is to describe methodically the main specifics and forms of technology planning/TS through the comprehensive study of available professional literature. The second goal is to analyze the development of technology planning methods, based on the bibliometrical analysis of ScienceDirect database (1823-2013). Main goals, individual explanations, practical examples, statistics and graphical information should help explain how technology planning currently looks like, what are its main priorities and problems.
\end{abstract}

Keywords: Integrated technology management, Technology planning, Technology strategy

\section{INTRODUCTION}

"Any innovation activity is ultimately aimed only at ensuring that the company remains in the same place." (Gibbons and Connor, 2003)

The dynamic development in all areas of business brings shorter life cycles of products, technologies, as well as organizational structures and enterprises. The critical factor of technological competitiveness is not a technology innovation process, but to find a new application for an existing technology (Rycroft, 2006). This change requires new investment, information, knowledge and other capabilities, which often lead to the higher labour mobility or multisourcing, to the use of various forms of flexible organizational structures and risk capital for research and development $(\mathrm{R} \& \mathrm{D})$, but also to the need to improve the cooperation with competitors, customers, suppliers, government institutions, etc. This in turn leads to the need for greater complexity of business plans, to the interactive connections with innovation and technology strategies, to specialization of enterprises and their parts so as to increase efficiency of internal (also technological) processes, but also to protect own know-how.

Generally, small and medium enterprises (SMEs) are more competitive able as regards to the use of emerging technological inventions and know-how, while larger companies have more capacities for own R\&D and planning, but also more cost advantages. SMEs do not usually have formulated an explicit technology strategy (TS), while adapting their technological activities to the general market development (Lee and Lee, 2008). Large manufacturing companies mainly formulate their TS, but often do not have enough flexibility to innovate own technologies as the market changes. If SMEs improve their technological know-how and innovation even internationally, 
becoming more able to participate in global value networks, and thus can cooperate with more suitable partners. Thus, a unilateral dependence on technological support of one enterprise changes into bilateral and multilateral cooperation with synergetic advantages, or with a new technology as a result of this collaboration (Davenport et al., 2003). For example, one of the competitive tasks of the management in IBM is continuous integration of the technology strategy with the business strategy to increase efficiency and a potential for business growth. Better TS is also an opportunity for an organizational change and improvement. The IBM's TS is mainly focused on the following key questions:

a) How can the company get a maximum value from its technology?

b) How is it possible to drive the business competitiveness and innovation through the technology?

c) How technologies can support business processes? Etc. (IBM, 2010)

In IBM, any technological infrastructure needs to support also business integration, security processes and know-how management. Then, technology investment and innovation can be also evaluated based on the following criteria: established business and technological integration. The quality of technological synergies does not only improve market competitiveness, but also allows obtaining faster and more precise information on the dynamics of the environment, socalled Real-time analytics (Andriole, 2006).

\section{INTRODUCTION TO THEORETICAL BACKGROUND OF TECH- NOLOGY STRATEGIES}

Technology strategy (TS) has been defined as a set of technology and related objectives, variant scenarios, technology roadmaps, targeting practices and know-how aimed at an adequate specification of the desired longterm development of a technological system and related processes $(\mathrm{R} \& \mathrm{D}$, supply, sales, control, service, etc.) (Wonglimpiyarat, 2012). TS has the main purpose to direct, develop and use appropriate technological facilities, processes and capabilities to meet strategic business objectives through the technology (Kyläheiko et al., 2011). However, there shall be an interactive two-way relationship between a business strategy and TS. Simple TS - as a source of information for a business strategy, or - as a tool for the implementation of a business strategy is hardly applicable in the dynamic technological environment.

The basis for each TS formulation should be a systematic SWOT analysis of a technology system and its determinants and effects (Friedman, 2005). Before formulating TS, a company should establish an appropriate technology vision and mission (Friedman, 2005), which must be in line with a vision and mission of the company. The formulation of TS consequently requires the identification of appropriate technological objectives and implementation plans/programs (a horizon, a budget, integration with an existing technology, staff training, organization changes, etc.). Technological objectives should be in line with strategic business objectives. In this context, it is necessary to update TS regularly in accordance with changes in the environment and in a business strategy, as well as with changes of technological processes. Flexible TS implies a set of regular follow-up decisions and planning activities related to the updating of technological processes (Gibbons and Connor, 2003). It is necessary to examine and record the continuity of these decisions and related 
factors to prolong the life cycle of a technology and for greater competitiveness of technology processes. The new TS often requires a new form of motivation and training for technology managers and employees to more effective actions (Davenport et al., 2003). In the current TM practice, we can identify for example the following categorization of technology strategies, Table 1:

Tab. 1 - Proposed categorization of possible forms of technology strategies. Source: own.

\begin{tabular}{|c|c|c|}
\hline \multicolumn{2}{|r|}{ Criterion } & Form of TS \\
\hline$A$. & Primary orientation of TS & Internally and Externally oriented TS \\
\hline$B$. & Relationship to business strategy & Cost leadership and Differentiation TS \\
\hline$C$ & $\begin{array}{l}\text { Location in so-called Product strategic } \\
\text { clock. }\end{array}$ & $\begin{array}{l}\text { Cost leadership TS, Differentiation TS, TS } \\
\text { with predominance of cost leadership, TS with } \\
\text { predominance of differentiation }\end{array}$ \\
\hline$D$. & $\begin{array}{l}\text { Ratio of internal and external orientation } \\
\text { of TS }\end{array}$ & $\begin{array}{l}\text { Cost-, Resource-, Process- and Market-oriented } \\
\text { TS }\end{array}$ \\
\hline E. & Specialization of business strategy & Specialized and Diversified TS \\
\hline$F$ & Scope of technological activities & Local, Regional, National or Global TS \\
\hline$G$ & Scope of business activities & $\begin{array}{l}\text { Alliance TS, Business TS, Partial TS for a } \\
\text { particular unit }\end{array}$ \\
\hline$H$. & Time aspects & Project, Program and Long-term TS \\
\hline$I$. & Compilation method & One or more variants of TS \\
\hline$J$ & Entrepreneurial focus & Production and Service-oriented TS \\
\hline$K$. & Support for domestic capacities & $\begin{array}{l}\text { TS on the use of domestic capacities } \\
\text { (Bid-oriented TS) and TS focused on the } \\
\text { development of domestic capacities (Demand- } \\
\text { oriented TS) }\end{array}$ \\
\hline
\end{tabular}

In the text below, we briefly describe selected forms of TSs for their better applicability. In the context of primary orientation of TS we can identify two extreme possibilities, i.e. Internally and Externally oriented TS:

a) Internally oriented technology strategy (Technology push, Cost-and Resource-based TS) is focused on the effective use and continuous improvement of internal technological processes, techniques, know-how or capacities to meet strategic goals of a company. In this strategy, special attention is given to continuous monitoring of internal technological processes, costs, resources and capacities to achieve the highest possible efficiency of the technology system and to systematically seek ways to improve it. Many internal capacities have an intangible form (knowhow, information, culture, tacit knowledge, etc.), which are very difficult to quantify, and often require an expert discussion, or services of a specialized company. Therefore internally oriented TS is more suitable for SMEs with some very specific technological know-how (Cartier, Raymond Weil, etc.), or for research companies and centers, which developing new technologies and products (Fraunhofer Gesellschaft, Centre National De La Recherche Scientifique, etc.) But, Technology-push TS also requires a proper market assessment of performance criteria and market requirements and trends (Maine et al., 2005). 
b) Externally oriented TS (Market-pull, Process- and Market-oriented TS) is focused on activities so as to take maximal advantage of market opportunities, to improve own technology system and to achieve strategic business objectives. An enterprise can take advantage of technology acquisitions or transfers, joint technological research, or funding joint research, access to clusters or strategic alliances, outsourcing, etc. In the last 10 years, there has significantly increased dependence of technology companies on external sources of technology innovation (McIvor, 2009), and about 45\% of technological innovation comes from external sources (Linder et al., 2003). Many companies that sell their products to final customers use more market-pull TS (Caetano and Amaral, 2011).

But, these strategies are usually the extreme forms, because a company can not only externally develop its own technology, if not systematically assessing and improving its own technological processes and capacities. And, a company can not normally improve its technological processes only from internal resources. For example, the Cisco's ecosystem TS takes advantages of the next generation of own technologies, but also of purposeful external mergers and acquisitions to keep up competitive advantages and to support own R\&D (Li, 2009). Therefore, there are the most frequently used various combinations of internally and externally oriented technology strategies (Figure 1):

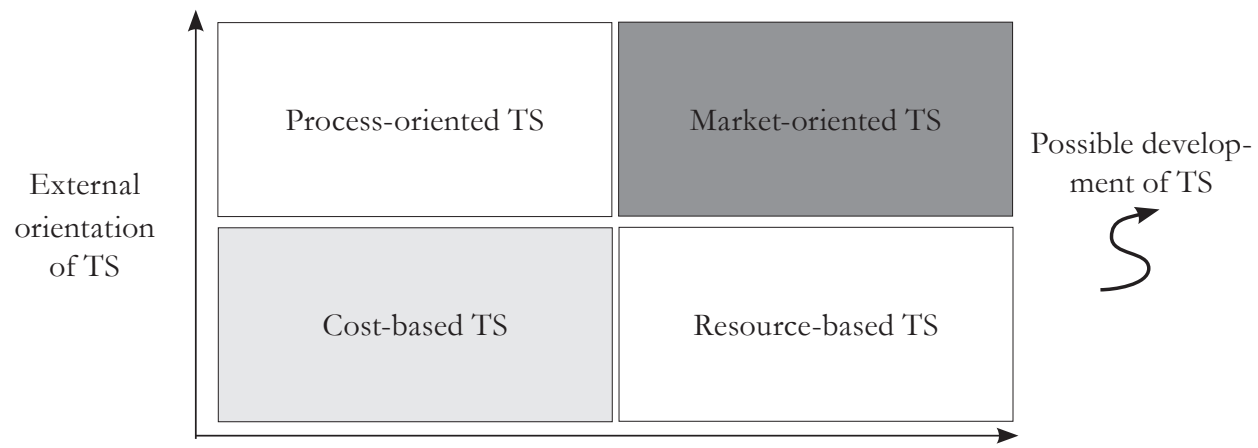

Internal orientation of TS

Fig. 1 - Model orientation of technology strategies. Source: own.

a) Cost-based TS is aimed at improving the competitiveness of a company through the monitoring and reduction of technologic and associated costs (less material and energy consumption, lower labor intensity of technological processes, etc.). Lower technology costs mean lower production costs, but also the reduction of some non-productive costs associated with the higher efficiency of administrative processes and reducing other overhead costs (lower depreciation costs, rents, annuities, etc.), which can be reflected in lower total costs of the company. The main problem of Cost-based TS is that it is often easily imitable, and therefore it is more difficult for a company to sustain such the competitive advantage in the long term. This TS is usually used by SMEs, although, larger enterprises can have higher economies of scale. For example, IBM was among the first SW vendors that used a tiered-pricing plan based on a type of Cost-based TS. This plan is based on the categorization of processors for its mainframe computers. Each category represents 
an attempt to decrease the cost by linking SW product costs to a perceived customer value. Costs to the customer are increased if SW is used on a more powerful system, increasing profits for IBM (Harmon et al., 2004).

b) Resource-based TS is focused on the development of strategic technological resources/capacities that a firm owns. A basis for a competitive advantage is the systematic development of all technological resources/capacities, whether material, or immaterial (technological know-how, tacit knowledge, intuition in TM, etc.). For example, it could be said that Microsoft and Apple might have similar some technology resources, but there is something more unique and innovative about Apple's products such as iPods, iPads, iPhones and $i$ Tunes that allow the company to be a more successful (ACCA, 2010). Therefore, prospective TS formulation requires a unique approach that can fully fulfill the current and future capacity needs of the company and potential risks of the technology (Fein, 2001). Building and development of technological capacities should be in accordance with the following principles:

- Efficiency - to direct TS and technological processes at improving the efficiency of the whole organization, but this requires that the technology itself was effective and purposeful. For example, many companies use their expensive SW only for $5-10 \%$.

- Complexity - to ensure that the building of internal technological capacities is in line with current and anticipated demands and needs of all stakeholders, particularly shareholders and customers.

- Sustainability - to make technological capacities more sustainable and upgradeable in line with the dynamic environment, but also with the social and environmental acceptability of the technology. Sustainable technological capacities building is a long-term process that requires long-term investment and efforts.

- Flexibility - to ensure that all technological capacities are adequately adaptable, not only within an enterprise, but also locally, nationally or internationally. This requires their wider compatibility and an adequate substitution of inefficient parts of the technology (Abuelma'atti, 2008). For example, the application of marketing know-how from one market segment to another is proved to be crucial in the use of free technological capacities, which is especially needed in the high-tech industry (Davenport et al., 2003).

c) Process-oriented TS allows a company to take advantage of open technological cooperation for more effective technology acquisitions, outsourcing, and transfers as well as of the internal intellectual property management. It is anticipated that just an open innovation strategy can spur more disruptive technology innovation (Yu and Hang, 2011). This TS can be prepared by using different ICT applications, which help monitor, model, plan, manage and improve technological processes of a company. This TS is focused to gain and maintain the competitive advantage through the effective implementation of key technological processes, for example, through investment in better staff training and motivation. In addition, this TS should enable to improve non-production technological operations of the company as well (supply, marketing, administration, monitoring, etc.). As another advantage, there can be different "spin-off" benefits resulting from active outsourcing or transfers of the technology. This strategy is more suitable for technology-oriented businesses. For example, at Accenture, the underlying collaboration technologies are embedded in the applications that workers use to execute targeted business processes. As the 
technology develops in cooperation, they also expect creating new knowledge about the business processes in which the technology is embedded, and incorporating the new knowledge of the process to provide more targeted, proactive collaboration assistance (Buller and Kass, 2012).

d) Market-oriented TS should be linked to market-oriented business and production strategies. The purpose of this TS is to identify, develop and implement better technologies (from internal and external sources), in order to offer customers a better quality and prices of products or services than competitors. This TS should also benefit from an open innovation strategy in areas where it is advantageous (e. g. joint R\&D and testing of technologies, etc.). But, this TS should also enable a company to take advantage of internal specialization in areas with maximal protection of critical business know-how. Then, the change in TS must be evaluated on the basis of the final market success. If customer needs and preferences are stable, this TS can be well definable and applicable (Fein, 2001). The problem may arise when there is higher instability of customer preferences and the market environment. Then, this TS requires not only systematic market analyzes, but also to educate employees and customers (or customers' customers) on business and market needs and risks (current and potential). Market-oriented TS can be an important tool to operationalize a business strategy as well. Market-oriented TS has traditionally been understood as far for focusing on customer-oriented R\&D of new products and necessary technologies in accordance with a business strategy (Aijo and Blomqvist, 2003). However, in the dynamic environment; R\&D, technology, production and organizational structures require individual solutions, interactively using all available resources and capacities, which must be individually adaptable and compatible. Therefore, this TS may require variant scenarios for individual components of the technology. Market-oriented international TS is usually used by global corporations. As an example of market-oriented technology cooperation, Ford and Microsoft cooperate to develop the SYNC in-car communications and entertainment system. With voice activation, SYNC lets drivers control their phone or iPod, listen to text messages, etc. (ARM, 2013) Meanwhile, Ford has been adapting its market-oriented TS to address evolving customer needs for more than 100 years and Microsoft for almost 40 years.

TS can have two main purposes: to meet goals of a business strategy and achieving goals of strategic business units' (SBUs) strategies. Regarding the link of a business strategy and a technology, differentiation TS (DIF TS) is preferable, which usually means a higher competitive advantage, value added and profit for the company. In terms of meeting goals of a SBU strategy, cost leadership TS (CL TS) is better so as to achieve possible quicker return on technology investment. Both options are extreme and therefore an enterprise must adapt TS to current business opportunities and market requirements. The typical example is now Apple and its iPhone. The company applies the TS, which should raise specific market dominance in a particular area. This differentiation is not in a pure form, since the core of this TS is market segmentation into two categories. The first category consists of current mobile services: voice, text, MP3, radio, TV, and others that also provide other companies. A second category is so-called a platform, which provides access to web browsing, e-mail (from Microsoft), sophisticated multimedia applications (including games) and other applications that may be installed on a normal PC.

TS should also complement other business plans in order to optimize relations: a purpose and performance of technology - technology efficiency - strategic business goals. Then, the purpose, performance and efficiency of technology should be set so as to fulfill better partial busi- 
ness objectives in the long term. However, it is necessary to have TS in accordance with external requirements as well in order to implement such a technology that will be accepted by the public. If we want to illustrate how each TS prioritizes the various parameters of production, it is useful to classify each TS to one of these groups, both in terms of a product multi-criteria analysis, socalled Product strategic clock (Figure 2).

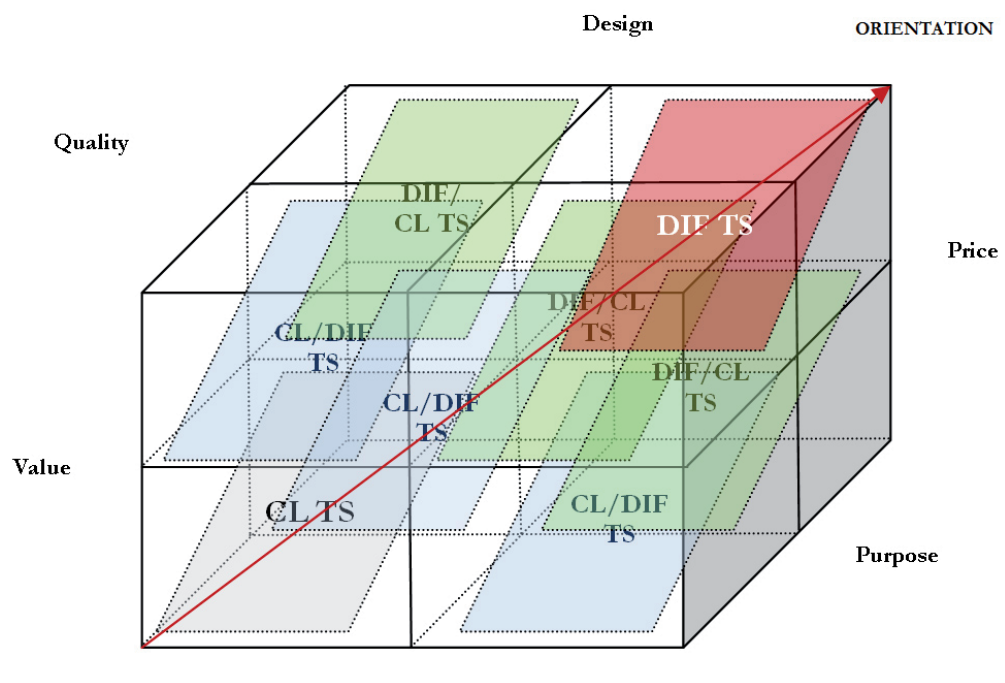

Lifetime

Fig. 2 - Application of „Product strategic clock" in formulation of TS. Source: own.

Then we can identify two other possible forms of TS, TS with predominance of cost leadership (CL/ DIF TS) and TS with predominance of differentiation (DIF/CL TS). CL/DIF TS can be used predominantly if lower demands on parameters of a product exist. For example, in the automotive industry, these are mostly brands like Suzuki, Opel, Fiat, etc. DIF/CL TS is used if higher demands on the parameters of a product are required. These are brands such as Honda, Volkswagen, Alfa Romeo, etc.

In terms of the width of technological activities we can identify local, regional, national or global technology strategies. Enterprises with international R\&D capacities, or with open technology strategies, often also have more complex technological capacities and competencies (Medcof, 2000). Global corporations often use global TS, but this is to a large extent timely and sectorally conditioned. For example, Oracle's PeopleSoft applications are designed for implementation in global corporations. PeopleTools is designed so that the applications can be used in different areas: users can share the same data while operating in different languages and applying different date, time, or numeric formatting conventions. (Oracle, 2013). At first, enterprises typically use for technological innovation all benefits and capacities of a domestic environment and choose a local or regional TS. With the growth of market coverage, companies apply national and international TS. 
Meanwhile, based on the specialization of a business strategy we recognize Specialized and Diversified TS. In terms of time aspects, we can identify Project, Program or Long-term TS. In terms of the scope of business activities we can recognize an Alliance, Business or Partial TS for a particular unit. According to the method of compilation, there may be one or more variants of TS. Based on the entrepreneurial focus we can identify Production and Service-oriented TS. Furthermore, there is TS on the use domestic capacities (Bid-oriented TS) and TS focused on the development of domestic capacities (Demand-oriented TS). Bid-oriented TS is focused to ensure adequate protection, marketing, transfer or outsourcing of technologies. Demand-oriented TS is focused on appropriate and effective R\&D and innovation of technologies.

\section{PROPOSED CATEGORIZATION OF KEY TECHNOLOGICAL PLANNING METHODS IN CONTEXT OF BIBLIOMETRICAL ANALYSIS}

Most of the methods used in technology planning might be classified as either normative or exploratory; these two types must be meshed for complete TS. But, Technology planning (TP) also requires a more holistic approach that supports planning of unpredictable technology impacts as well and impacts indirectly related to the technology. One of the solutions to ensure proper assessment of entities of a technological system is to use so called Furzy logic (Multi criteria intuitive logic) (Ross, 2010). Fuzzy logic is especially used for Technology assessment. The problem of planning technology entities largely depends on other issues and problems of TP. Among the key problems associated with TP:

A. Demands of TM are exaggerated. TS has to solve too many problems of the company or to ensure the achievement of too many unrelated goals.

$B$. There is no continuity of TS to a business strategy and goals.

C. There are not defined clear criteria for TS, or there are different criteria used by different stakeholders. Stakeholders are wrongly chosen and informed about the technology, evaluation criteria and evaluation processes.

$D$. The whole planning process is improperly organized; there is no feedback, or too little time to prepare TS. Problems of the technology are limited in time and the TS does not fit into this interval. E. Principal causal dependencies (in terms of technology innovation effects at some time) are no longer actual (Ludwig, 1998).

F. Too many people taking part in the final decision about the technology. Etc.

If we look at the development of technology planning methods based on the Bibliometrical analysis a scientific method (Bellis, 2009) then we can identify certain trends (Table 2). We can notice that the most applied methods are Modelling and Simulation, Scenarios writing, and Interviews. From the time perspective, the most applied methods are Forecasting, Historical analogy, and Modelling and simulation. Many methods have become more applied only after the year 2000, which can be linked to higher perceived risks of the global environment by many institutions. One of the first articles on Technology modelling/planning entitled: 'Computer applications in state planning' was published in 1968. The author described the U.S. Statewide Planning Program based on the uses of computers to compile, tabulate, manipulate, and forecast data. (Varin, 1968) 
Tab. 2 - Development of key technology planning methods - Number of scientific articles. Source: Sciencedirect, 2013

\begin{tabular}{|c|c|c|c|c|c|}
\hline Methods & -1970 & -1980 & -1990 & -2000 & -2013 \\
\hline Modelling a simulation & 4 & 57 & 396 & 1925 & 8800 \\
\hline Scenarios writing & 1 & 29 & 152 & 614 & 3932 \\
\hline Interview & 0 & 8 & 81 & 284 & 1605 \\
\hline Questionnaire & 0 & 13 & 78 & 293 & 1589 \\
\hline Key technologies & 0 & 0 & 27 & 199 & 1038 \\
\hline Workshop & 2 & 25 & 163 & 434 & 950 \\
\hline Forecast & 7 & 59 & 151 & 312 & 851 \\
\hline Regression analysis & 0 & 6 & 33 & 104 & 501 \\
\hline Essays writing & 0 & 8 & 37 & 116 & 279 \\
\hline Historical analogy & 5 & 11 & 25 & 89 & 274 \\
\hline Benchmarking & 0 & 1 & 4 & 34 & 241 \\
\hline Extrapolation & 1 & 13 & 39 & 89 & 235 \\
\hline Delphi & 4 & 13 & 22 & 63 & 193 \\
\hline Diffusion model & 0 & 0 & 4 & 27 & 145 \\
\hline Voting & 0 & 1 & 7 & 23 & 94 \\
\hline Literature survey & 0 & 1 & 5 & 14 & 93 \\
\hline Patent analysis & 0 & 0 & 0 & 2 & 90 \\
\hline Bibliometrical analysis & 0 & 0 & 4 & 19 & 73 \\
\hline Petri-Nets & 0 & 0 & 3 & 16 & 71 \\
\hline Roadmapping & 0 & 0 & 0 & 1 & 68 \\
\hline Analytic hierarchy process & 0 & 0 & 1 & 7 & 59 \\
\hline Expert panel & 0 & 1 & 2 & 15 & 57 \\
\hline Multi-criteria analysis & 0 & 0 & 0 & 10 & 57 \\
\hline S-curve analysis & 0 & 0 & 2 & 12 & 54 \\
\hline SWOT analysis & 0 & 0 & 0 & 4 & 48 \\
\hline Econometrics & 0 & 2 & 5 & 10 & 43 \\
\hline Morphological analysis & 1 & 1 & 6 & 11 & 42 \\
\hline Brainstorming & 0 & 0 & 2 & 11 & 36 \\
\hline Utility analysis & 0 & 0 & 0 & 7 & 33 \\
\hline Contingency theory & 0 & 1 & 3 & 9 & 27 \\
\hline Think tank & 0 & 2 & 2 & 7 & 18 \\
\hline
\end{tabular}

Table 2 was compiled based on the Bibliometrical analysis, the stated numbers refer to the numbers of scientific articles published in refereed scientific journals and books registered in the Sciencedirect databasis. Based on the number of scientific articles we can identify to some extent, how these methods were applied. 
Individual forms of TP require the use of a combination of individual analytical, assessment and planning methods, which depend on a type of technology, its complexity, a scope of TP, a time interval, availability of information, as well as individual requirements on TP (a budget, legislative rules, a method of technology acquisition, etc.).

\section{DISCUSSION AND CONLUSIONS}

If we look at the development of technology planning in terms of the particular Bibliometrical analysis, then we can notice that the most developed sub-discipline of technology planning is just Foresight (Jemala and Svatý, 2010), even from the time perspective. The concept of technology strategy (TS) has always been tied to the development of other managerial processes and changes in the environment. TS increasingly influences areas like interactions created between a company and the environment, a positive change in a business structure, new enterprise culture, or a better access to the market (Jemala, 2008). For SMEs, some aggressive extensive TS could mean, in case of failure, significant effects on other business capacities and economic results. For larger companies, in turn, a long-term strategy of a market follower could mean incomplete utilization of capacities and resources, and thus the lower technology competitiveness, as well as worse economic results. For a dynamic technological company in a less dynamic environment could dynamic TS mean the improvement of production parameters, but also the overpriced facilities, and less competitive results. Conversely, a long-term strategy of a technological follower in the high-tech technological environment may indeed lead to reduced costs of R\&D, but such the company would never be a market leader, will have weaker goodwill, and then again worse economic results.

In the context of primary orientation of TS we can identify two basic forms, i.e. Internally and Externally oriented TS. But, these strategies are usually the extreme types, because a company can not only externally develop its own technology, if not systematically assessing and improving its own technological processes and capacities. Regarding the main link of a business strategy and technology, Differentiation TS is preferable, which usually means a higher competitive advantage, value added and profit for the company. In terms of meeting goals of a SBU strategy, Cost leadership TS is better so as to achieve possible quicker return on technology investment. Based on the Bibliometrical analysis, we identified that the most applied methods in technology planning might be Modelling and Simulation, Scenarios writing, and Interviews. The more intensive use of Modelling and Simulation methods in technology planning is obviously related to the development of ICT, but also to the increasing requirements on the complexity of technology strategies. We can also notice that technology planning is currently strongly conditioned by external analyses; but it has a more internal formal nature, more numerical data are used, which are subsequently assessed by experts. These findings are of course determined by the individual characteristics of a technology, a company, an industry, a region, etc.

\section{References}

1. Abuelma'atti, M. T. (2008). Building Engineering and Technology Capacity in the Arab Countries. Paper presented at the 2nd Conference on Planning \& Development of Education and Scientific Research in the Arab States, February 24-27, 2008. King Fahd University of Petroleum \& Minerals, Dhahran - Saudi Arabia. 
2. ACCA. (2010). Position-based and Resource-based strategies. Retrieved from: http://www. accessmylibrary.com/coms2/summary_0286-24887607_ITM

3. Aijo, T., \& Blomqvist, K. (2003). Integrating a customer-oriented technology strategy with general business strategy. Paper presented at the12th IAMOT Conference, May 12-15, 2003. Nancy, France.

4. Andriole, J. S. (2006). The Collaborate/Integrate Business Technology Strategy. Communication of the ACM, 49(5), 85-90. http://dx.doi.org/10.1145/1125944.1125946

5. ARM. (2013). Ford Sync In-Car Communications \& Entertainment System. Retrieved from: http:// www.arm.com/markets/embedded/ford-sync-in-car-communications-entertainmentsystem.php

6. Bellis, D. N. (2009). Bibliometrics and citation analysis: from the Science citation index to cybermetrics. Maryland: Scarecrow Press.

7. Buller, J., \& Kass, A. (2012). Integrating Collaboration Technology Deeply into Business Process and Applications. Accenture. Retrieved from: http://www.accenture.com/ SiteCollectionDocuments/PDF/Accenture-Integrating-Collaboration-Deeply-intoBusiness-Process.pdf

8. Caetano, M., \& Amaral, D. C. (2011). Roadmapping for technology push and partnership: A contribution for open innovation environments. Technovation, 31(7), 320-335. http:// dx.doi.org/10.1016/j.technovation.2011.01.005

9. Davenport, S., Campbell, C., \& Solomon, J. (2003). The Dynamics of technology strategy: an exploratory study. R\&D Management, 33(5), 481-498. http://dx.doi.org/10.1111/14679310.00312

10. Fein, A. (2001). Build a Customer-Driven Technology Strategy. Metal Centre News, August, 4-7.

11. Friedman, G. H. (2005). Technology strategy an investment in your business. Journal of Financial Planning, 18(7), 30-32.

12. Gibbons, P. T., \& O’Connor, T. (2003). Strategic posture, technology strategy and performance among small firms. Journal of Enterprising Culture, 11(2), 131-146. http://dx.doi. org/10.1142/S0218495803000081

13. Harmon, R., Raffo, D., \& Faulk, S. (2004). Value-Based Pricing for New Software Products: Strategy Insights for Developers. Paper presented at the PICMET/STEPI conference, July 31 - August 4. Seoul, Korea.

14. IBM. (2010). Technology strategy: Overview. Retrieved from: http://www-935.ibm.com/ services/us/index.wss/offerfamily/gbs/a1029389

15. Jemala, L. (2008). Plánovanie ako funkcia manažmentu. In Podnikatel'ský manažment a marketing. Bratislava: Vydavatel'stvo STU.

16. Jemala, M. (2010). Evolution of Foresight in the Global Historical Context. Foresight, 12(4), 65-81. http://dx.doi.org/10.1108/14636681011063004

17. Jemala, M. (2011). Management of Technology Systems: Identification and Case studies. Bratislava: Economist.

18. Jemala, M. (2012). Nature of Foresight Planning. Saarbrücken: Lambert Academic Publishing. 
19. Jemala, M. (2013). On global sustainability and regional environmentally oriented foresights. International Journal of Agile Systems and Management, 6(2), 118-140. http://dx.doi. org/10.1504/IJASM.2013.053806

20. Jemala, M., \& Svatý, F. (2010). Ontológia foresightu: Podnety pre tvorbu vizie SR na báze metodiky foresightu. Bratislava: Ekonóm.

21. Kyläheiko, K., Jantunen, A., Puumalainen, K., \& Luukka, P. (2011). Value of Knowledge - Technology Strategies in Different Knowledge Regimes. International Journal of Production Economics, 131(1), 273-287. http://dx.doi.org/10.1016/j.ijpe.2010.07.009

22. Lee, Y-J., \& Lee, J-D. (2008). Technology strategy for enhancing the public-to-private technology transfer: evidence from the duration of patent. Applied Economics, 40(2), 229-240. http://dx.doi.org/10.1080/00036840600749854

23. Li, Y. R. (2009). The technological roadmap of Cisco's business ecosystem. Technovation, 29(5), 379-386. http://dx.doi.org/10.1016/j.technovation.2009.01.007

24. Linder J. C., Jarvenpaa, S., \& Davenport, T. H. (2003). Toward an innovation sourcing strategy. MIT Sloan Management Review, 44(4), 43-49.

25. Ludwig, B. (1998). Fuzzy logic applications in technology assessment studies. Journal of Intelligent and Fuzzy Systems, 1(6), 375-388.

26. Maine, E., Probert, D., \& Ashby, M. (2005). Investing in new materials: a tool for technology managers. Technovation, 25(1), 15-23. http://dx.doi.org/10.1016/S01664972(03)00070-1

27. McIvor, R. (2009). How the transaction cost and resource-based theories of the firm inform outsourcing evaluation. Journal of Operations Management, 27(1), 45-63. http://dx.doi. org/10.1016/j.jom.2008.03.004

28. Medcof, J. W. (2000). The Resource-based View and Transnational Technology Strategy. The Journal of High Technology Management Research, 11(1), 59-74. http://dx.doi.org/10.1016/ S1047-8310(00)00021-3

29. ORACLE. (2013). PeopleTools 8.53: Global Technology. Retrieved from http://docs.oracle.com/ cd/E39332_01/psft/acrobat/pt853tgbl-b0213.pdf

30. Ross, T. J. (2010). Furzy Logic with Engineering Applications. Chichester: Wiley-Blackwell. http://dx.doi.org/10.1002/9781119994374

31. Rycroft, R. W. (2006). Time and technological innovation: Implications for public policy. Technology in Society, 28(3), 281-301. http://dx.doi.org/10.1016/j.techsoc.2006.06.001

32. SCIENCEDIRECT. (2013). Search. Retrieved from: http://www.sciencedirect.com/ science?_ob=MiamiSearchURL\&_method=requestForm\&_btn=Y\&_zone=TopNavBar\&_ origin=home\&_acct $=$ C000051056\&_version=1\&_urlVersion=1\&_userid=1052399\&md5= 6d0d8f5406684e929845851f33b1a05c

33. Vavrin, D. W. (1968). Computer applications in state planning. Socio-Economic Planning Sciences, 1(3), 335-344. http://dx.doi.org/10.1016/0038-0121(68)90020-7

34. Wonglimpiyarat, J. (2012). Technology strategies and standard competition - Comparative innovation cases of Apple and Microsoft. Management Research, 23(2), 90-102. http://dx.doi. org/10.1016/j.hitech.2012.06.005 
35. Yu, D., \& Hang, CH. CH. (2011). Creating technology candidates for disruptive innovation: Generally applicable R\&D strategies. Technovation, 31(8), 401-410. http://dx.doi.org/10.1016/ j.technovation.2011.02.006

\section{Contact information}

doc. Dr. Marek Jemala

School of Engineering and Management, University of Nova Gorica

Vipavska 13, Rožna Dolina, Nova Gorica, Slovenia

E-mail:marek.jemala@ung.si 